\title{
Reproductive Consequences in Obese Women
}

\section{Sharma I $1 *$ and Sharma A}

${ }^{1}$ Department of Zoology, Panjab University, India

*Corresponding author: Indu Sharma, Assistant Professor, Department of Zoology,

Panjab University, Chandigarh, India, Tel: +91-1722534205; E-mail: indu2702@pu.ac.in

\section{Editorial}

Obesity is a medical condition characterized by the presence of excess body fat which leads to various metabolic disorders [1]. Adult obesity is measured in the terms of Body Mass Index (BMI) (WHO Expert Consultation, 2004). A BMI of 19 to 25 is considered to be an ideal weight, while BMI above 25 is taken as overweight and obese. In a report, compiled by the American Institute for Cancer Research and World Cancer Research Fund, every five point increase in the BMI is associated with a six percent increase in the risk of developing ovarian cancer [2].

Obesity is a common problem among reproductive age women and is associated with numerous reproductive abnormalities like anovulation, irregular menses, subfertility and miscarriage. Adipokines, secreted by adipose tissue affect the hypothalamus-pituitary signaling, thus inhibiting ovulation and posing a mechanism by which obesity increases the risk of anovulation and irregularity in menstrual cycle [3]. Reproductive targets of obesity include the hypothalamus, the ovary and ovarian follicle, the oocyte, the embryo and the uterine endometrium.

Poretsky, et al. [4] reported insulin to play an important role in ovarian functions like follicular development, proliferation of granulosa cells and regulation of ovarian steroidogenesis. But obesity contributes for the development of type 2 Diabetes Mellitus which is characterized by impaired insulin signaling and increased blood glucose levels [5]. This results in insulin resistance and hence abnormal ovulation in obese women. Women who lose weight, experience reduction in insulin resistance and also tend to resume their normal ovulation [6]. Obesity is also linked with the high dose of medications required to stimulate ovulation for in vitro fertilization (IVF). Therefore, the women undergoing IVF are generally encouraged to maintain a healthy weight during treatment.

Obesity is a common finding in women with polycystic ovarian syndrome (PCOS). About $40-80 \%$ of women with this condition are reported to be overweight or obese. PCOS is a state of hormonal abnormality in which the female body produces an excess of the male hormones and the normal process of ovulation is disrupted. The eggs are either not matured or not released and thus appear as cysts in the sonogram. PCOS is associated with defects in insulin sensitivity and secretion which are further worsened by obesity [7].

Among women with $\mathrm{BMI}>30 \mathrm{~kg} / \mathrm{m} 2$, infertility chances are observed to be three times higher when compared with women of BMI $<30 \mathrm{~kg} / \mathrm{m} 2$ [8]. Many researchers have documented that women with $\mathrm{BMI}>25$ $\mathrm{kg} / \mathrm{m} 2$ have lowered levels of $\mathrm{FSH}, \mathrm{LH}$ and progesterone, shorter luteal phase and longer follicular phase when compared with women having BMI $<25 \mathrm{~kg} / \mathrm{m} 2$.

Obesity can also be held responsible for the increasing rates of miscarriages in obese women regardless of mode of conception. A meta-analysis study conducted on more than 16,000 patients revealed that there was a significant increase in the miscarriage rates in women with $\mathrm{BMI}>25$ $\mathrm{kg} / \mathrm{m} 2$ [9]. Risks of spontaneous abortions are positively correlated with maternal BMI as observed in analysis of 2,349 pregnancies achieved through Assisted Reproductive Techniques [10].

The probability of fetal and maternal morbidity is enhanced manifolds in obese women along with the risk of gestational diabetes, preeclampsia, hereditary abnormalities, stillbirth, fetal growth abnormalities and the need for cesarean delivery [11]. Maternal obesity is 


\section{International Journal of Zoology and Animal Biology}

also linked to fetal death not only in early pregnancy but in second and third trimester also. Obese mothers are strongly reported to have premature off springs due to the early induction of labor and cesarean section due to preeclampsia [12].

Obesity is a known risk factor for endometrial cancer. Abnormal hormonal profile and adipokine productioncharacteristics of obesity are the potent factors favoring endometrial carcinogenesis in obese women $[13,14]$. The International Agency for the Research on Cancer has described that the risk for developing cancer increases 3.5- to 2-fold in obese and overweight women respectively $[15,16]$. The negative effects of obesity on female reproductive health are well known, but an efficient remedy or cure for the same is yet to be explored.

\section{References}

1. Wyatt HR (2013) Update on Treatment Strategies for Obesity. J Clin Endocrinol Metab 98(4): 1299-1306.

2. Collaborative Group on Epidemiological Studies of Ovarian Cancer (2012) Ovarian cancer and body size: individual participant meta-analysis including 25,157 women with ovarian cancer from 47 epidemiological studies. PLoS medicine 9(4): e1001200.

3. Jain NJ, Denk CE, Kruse LK, Dandolu V (2007) Maternal obesity: can pregnancy weight gain modify risk of selected adverse pregnancy outcomes? Am J Perinatol 24(5): 291-298.

4. Poretsky L, Cataldo NA, Rosenwaks Z, Giudice LC (1999) The insulin-related ovarian regulatory system in health and disease. Endocrinol Rev 20(4): 535-582.

5. Akamine EH, Marcal AC, Camporez JP, Hoshida MS, Caperuto LC, et al. (2010) Obesity induced by high-fat diet promotes insulin resistance in the ovary. J Endocrinol 206(1): 65-74.

6. Clark MM, Guise BJ, Niaura RS (1995) Obesity level and attrition: support for patient-tre atment matching in obesity treatment. Obes Res 3(1): 63-64.
7. Sam S (2007) Obesity and Polycystic Ovary Syndrome. Obes Manag 3(2): 69-73.

8. Sim KA, Partridge SR, Sainsbury A (2014) Does weight loss in overweight or obese women improve fertility treatment outcomes? A systematic review. Obes Rev 15(10): 839-850.

9. Metwally M, Ledger WL, Li TC (2008) Reproductive endocrinology and clinical aspects of obesity in women. Ann N Y Acad Sci 1127: 140-146.

10. Wang JX, Davies MJ, Norman RJ (2002) Obesity increases the risk of spontaneous abortion during infertility treatment. Obesity 10(6): 551-554.

11. Catalano PA, Ehrenberg HM (2006) The short-and long-term implications of maternal obesity on the mother and her offspring. BJOG 113(10): 1126-1133.

12. Smith GC, Shah I, Pell JP, Crossley JA, Dobbie R (2007) Maternal obesity in early pregnancy and risk of spontaneous and elective preterm deliveries: a retrospective cohort study. Am J Public Health 97(1): 157-162.

13. Purdie DM, Green AC (2001) Epidemiology of endometrial cancer. Best Pract Res Clin Obstet Gynaecol 15(3): 341-354.

14. Kaaks R, Lukanova A, Kurzer MS (2002) Obesity, endogenous hormones, and endometrial cancer risk: a synthetic review. Cancer Epidemiol Biomarkers Prev 11(12): 1531-1543.

15. Bianchini F, Kaaks R, Vainio H (2002) Overweight, obesity, and cancer risk. Lancet Oncol 3(9): 565-574.

16. Calle EE, Rodriguez C, Walker Thurmond K, Thun MJ (2003) Overweight, obesity, and mortality from cancer in a prospectively studied cohort of U.S. adults. N Engl J Med 348(17): 1625-1638. 